\title{
Numerical contrast of flexible clamp and rigid clamp for stretch forming
}

\author{
Heli Peng ${ }^{1, \text { a) }}$, Zhongquan $\mathrm{Li}^{1, \text { b) }}$, Yiping Zhong ${ }^{1, \mathrm{c})}$ and Mingzhe $\mathrm{Li}^{2, \mathrm{~d})}$ \\ ${ }^{1}$ Shanghai Spaceflight Precision Machinery Institute, Shanghai 201600,China \\ 2 Dieless Forming Technology Research Center of Jilin University, Changchun, China

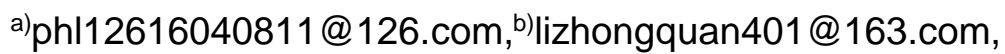 \\ c)hangtian402@163.com, d)limz@jlu.edu.cn
}

\begin{abstract}
Keywords: Sheet metal, Flexible clamp, Rigid clamp, Stretch forming, Numerical simulation
Abstract. The characters of flexible clamp stretch forming (FCSF) is introduced, the finite element model of FCSF is set up, and lots of numerical simulations for spherical part and saddle-shaped part are carried out. Contradistinctive analysis of strain, thickness and transitional length between RCSF and FCSF are investigated, and the minimum transitional length diagram of spherical part and saddle-shaped part are determined. FCSF machine was developed, and the forming experiment of spherical part was done. Consequently, the spherical part has good surface quality, which proves that the FCSF technology is feasible and the simulated results are valid.
\end{abstract}

\section{Introduction}

Compared to other forming operations, stretch forming operation has litter springback value and better shape precision, so it becomes the primary method to form aircraft outer skin parts. Most of the aircraft outer skin parts are stretched by rigid die and clamp. But traditional rigid fixed die is designed to form a particular part and offers no shape flexibility, which leads the fabricating cost of stretching die is generally high. And traditional rigid clamp has no relative movement between clamp and sheet metal, which leads the sheet is difficult to fit the die when forming parts with large transversal curvature.

In recent years, with the improvement of industrial level, the demands of sheet metal with complex shape and good forming quality increased rapidly in the field of aeronautics and astronautics. Flexible die and clamp are used to form parts with different shapes and improve the forming quality. Zhou [1] proposed the concept of multi-point stretch forming (MPSF) based on the multi-point forming (MPF) [2]. Cai [3] studied the effects of the elastic cushion, the punch element and the multi-point stretching die on the shape accuracy of the formed part in the MPSF. Wang [4] investigated the number of punch elements and the radius of the hemispherical end of elements on the surface smooth and the shape error of the formed parts in the MPSF. Adjustable clamp stretching machine was developed by ACB of France [5], but the machine needs to manually adjust the arc of sub-clamp based on the shape of stretching die, which leads to low forming precision and efficiency. Then, a new-type of flexible clamp stretch forming (FCSF) machine was designed [6]. It is attractive due to the flexibility of clamping method. The purpose of this paper is to investigate the difference between rigid clamp stretch forming (RCSF) and FCSF.

\section{The characters of FCSF}

The notable feature of the FCSF is that it has several sub-clamps in both side, and each sub-clamp is connected by a universal joint and a set of hydraulic cylinders, which consist of horizontal cylinder, vertical cylinder and leaning cylinder. The biggest difference between FCSF and RCSF is that the traditional rigid clamp is replaced by flexible discrete clamps and random curve shape can be formed by rotation of sub-clamp. Fig. 1 is the schematic diagram of FCSF, it can be found that the all sub-clamps are arranged into a horizontal line state when stretching begin, then the all sub-clamps make real-time position in according with the shape of stretching die during the stretching process, and the all sub-clamps come to a curve similar to the edge line of stretching die when stretching end. 


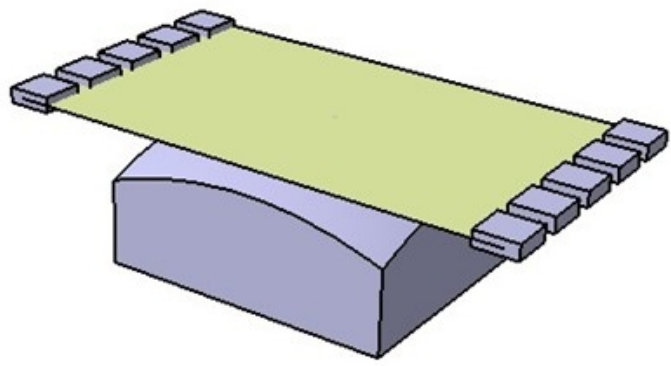

(a) Stretching begin

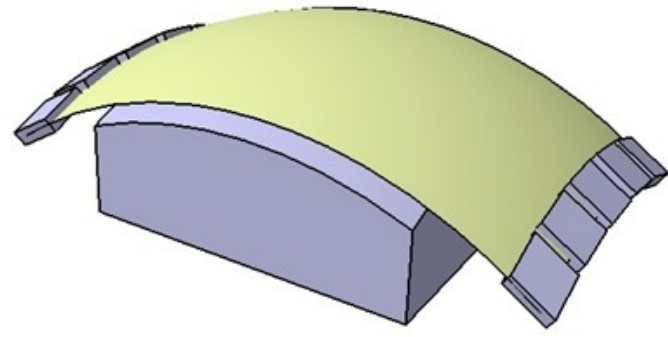

(b) Stretching end

Fig.1 The schematic diagram of FCSF

\section{Finite element model of FCSF}

Numerical simulation of spherical part and saddle-shaped part are performed by Abaqus. The radius of spherical part and the bidirectional radius of saddle-shaped part are both $500 \mathrm{~mm}$. The effective forming zone of die is $300 \times 300 \mathrm{~mm}$, and the initial size of sheet metal is $500 \times 300 \times 1 \mathrm{~mm}$. The physical-mechanical properties of $2024-\mathrm{O}$ are: Elastic modulus $E=40.54 \mathrm{GPa}$, yield strength $\sigma_{y}=77.5 \mathrm{MPa}$, Poisson's coefficient $\nu=0.33$ and density $\rho=2.78 \mathrm{~g} / \mathrm{cm}^{3}$. The real stress and strain curve of 2024-O obtained by uniaxial tensile test is shown in Fig.2.

The finite element model of FCSF is shown in Fig.3. Due to the symmetry, only a quarter of model is set up. The finite element model is composed of three parts: sheet metal, stretching die and clamp. The four-node quadrilateral shell element S4R is used to model the sheet metal. The stretching die and clamp are simplified as rigid shell and modeled with complicated rigid element R3D4. On the two symmetrical axes, the displacements normal to the axis and the rotations around the axis are constrained in the finite element simulations. The frictional coefficient of clamp-to-sheet metal is set to 0.5 , and the friction coefficient between stretching die and sheet metal is 0.1 . The stretching direction agrees with $y$-axis and the stretching velocity is $1 \mathrm{~m} / \mathrm{s}$.

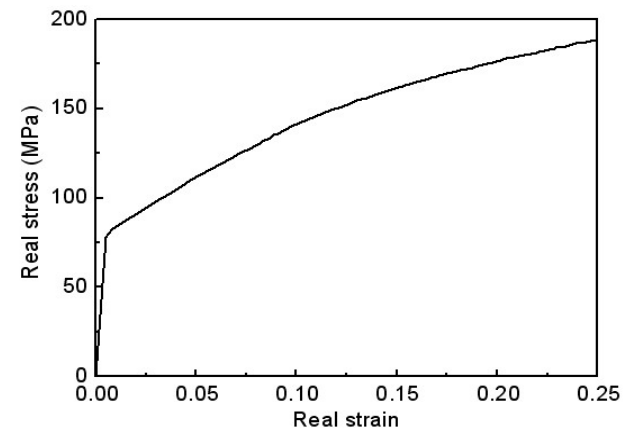

Fig.2 The stress-strain of 2024-O

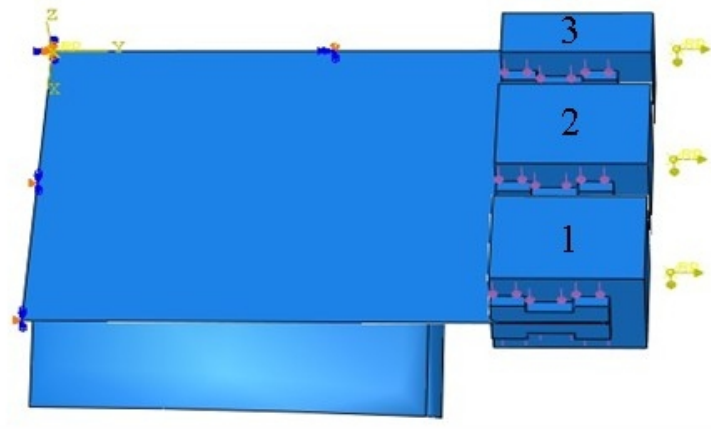

Fig.3 A quarter of finite element model

\section{Comparison between FCSF and RCSF}

Fig. 4 shows the equivalent strain of spherical parts formed by RCSF and FCSF. It can be found that the clamping zone appears line shape on the spherical part formed by RCSF and that appears curve shape on the spherical part formed by FCSF, which illustrate the sub-clamp has rotated in the FCSF process. What's more, the stress concentration emerge in the edge of clamping zone when RCSF, the maximum value of equivalent strain is $19.73 \%$, and the distribution interval of equivalent strain ranges from $2.13 \%$ to $12.92 \%$. While the maximum value of equivalent strain is $11.82 \%$ when FCSF, and the distribution interval of equivalent strain ranges from $2.05 \%$ to $9.98 \%$.Contrasting to DCSF, the maximum value and distribution interval of equivalent strain on spherical parts formed by FCSF decrease $40.1 \%$ and $26.5 \%$ respectively. 


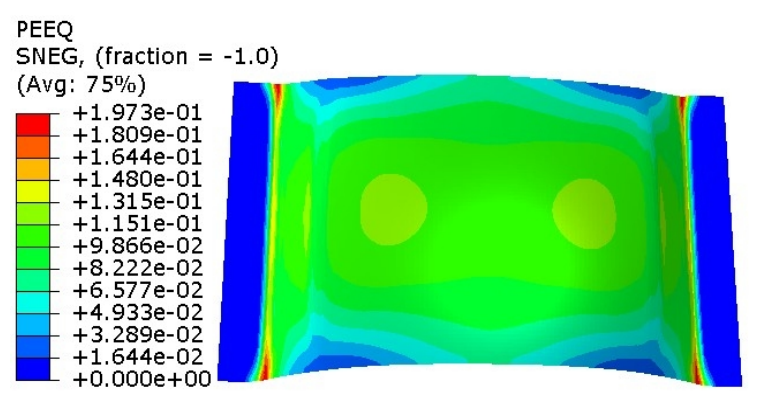

(a) RCSF

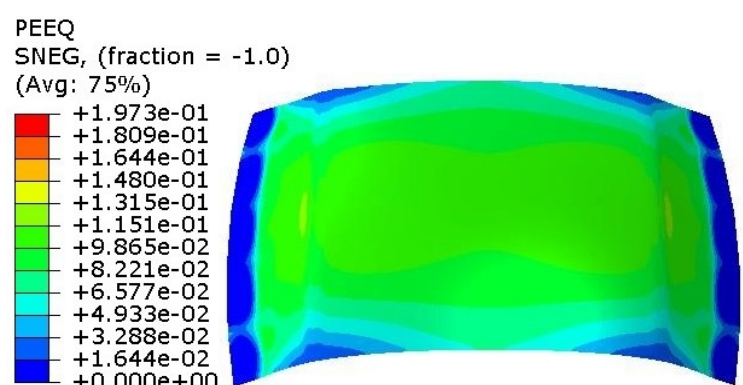

(b) FCSF

Fig.4 Equivalent strain of spherical part with different stretching methods

The thickness distribution of saddle-shaped part formed by RCSF and FCSF is shown in Fig.5. Obviously, the minimum thickness of saddle-shaped part appears in the edge of clamping zone for both RCSF and FCSF. The minimum thickness of saddle-shaped part formed by RCSF is $0.933 \mathrm{~mm}$, and that formed by FCSF is $0.966 \mathrm{~mm}$, which illustrates that the thinning ratio of FCSF declined 49.3\% compared with RCSF. The thickness interval of effective forming area with RCSF is $0.961-0.984 \mathrm{~mm}$, and that with FCSF is $0.966-0.984 \mathrm{~mm}$, which illustrate that a more uniform thickness distribution can be got by FCSF.

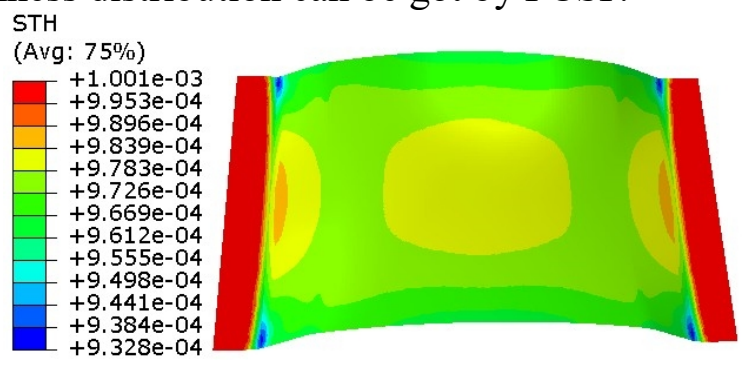

(a) RCSF

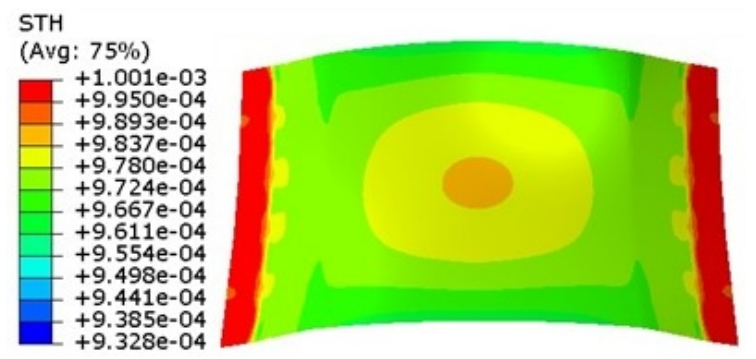

(b) FCSF

Fig.5 Thickness distribution of saddle-shaped part with different stretching methods

The minimum transitional length of spherical part and saddle-shaped part formed by RCSF and FCSF with different radii are presented in Fig.6. The following features can be found: firstly, the distribution trend of minimum transitional length is consistent between RCSF and FCSF for both spherical part and saddle-shaped part; secondly, the minimum transitional length decreases with the increasing of forming radius; thirdly, the minimum transitional length of RCSF is larger than that of FCSF. Taking the spherical part for example, when the radius is $300 \mathrm{~mm}$, the minimum transitional length of RCSF is $120 \mathrm{~mm}$, while the minimum transitional length of FCSF is $30 \mathrm{~mm}$, which illustrate that spherical part formed by FCSF can save the transitional length is $100 \mathrm{~mm}$. With the radius increasing to $1200 \mathrm{~mm}$, the minimum transitional length of RCSF is $20 \mathrm{~mm}$, while the minimum transitional length of FCSF is $15 \mathrm{~mm}$, and deviation of transitional length for both forming method is only $5 \mathrm{~mm}$. The reason is that a larger radius has a smaller transversal curvature, which leads to a smaller difference between RCSF and FCSF.

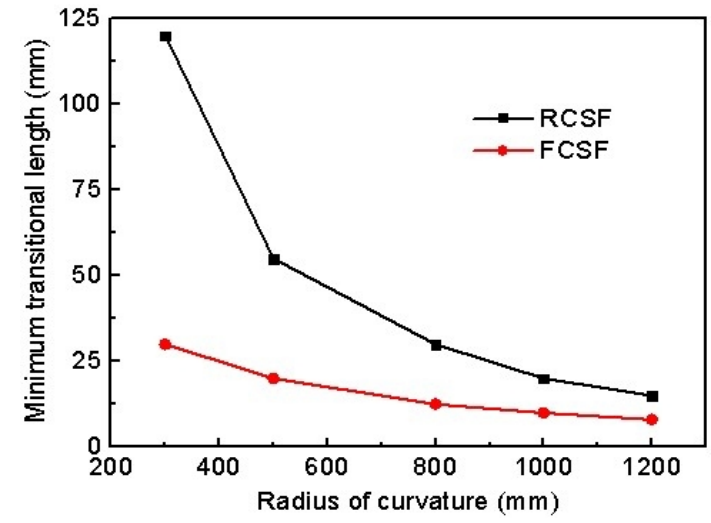

(a) spherical part

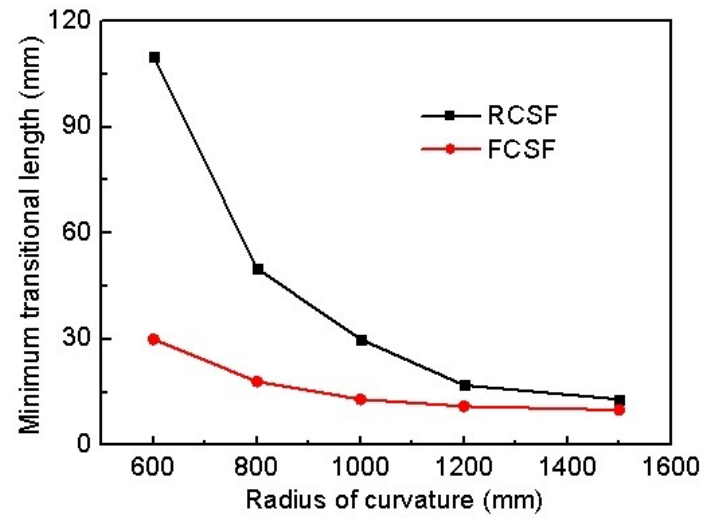

(b) saddle-shaped part

Fig.6 The minimum transitional length of RCSF and FCSF 


\section{FCSF Experiment}

In order to verify the numerical results, A new type of discrete clamp stretch forming machine based on flexible holding technology was developed by Dieless Forming Technical Center of Jilin University, as shown in Fig.7. And the FCSF experiment of spherical part with radius of 300 is carried out, the forming area is $300 \times 300 \mathrm{~mm}$, and the size of sheet metal is $440 \times 300 \times 1 \mathrm{~mm}$. Fig. 8 is the experimental result of spherical part, it shows the spherical part formed by FCSF has good surface quality, and the edge of blank is curve shape, which proves the feasibility of FCSF technology.

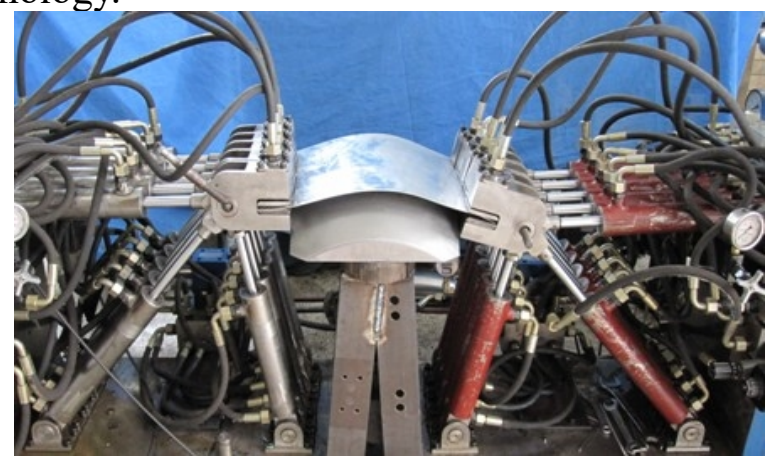

Fig.7 The FCSF machine

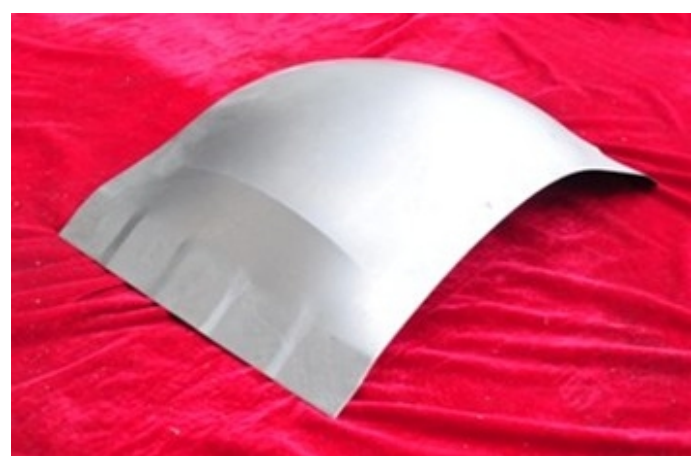

Fig.8 The experiment of spherical part

\section{Conclusions}

The forming character of FCSF is introduced, the RCSF and FCSF of spherical part and saddle-shaped part are simulated, and the equivalent strain, thickness and transitional length are investigated. The results show that 3D part formed by FCSF has a smaller equivalent strain and a thicker thickness contrasting to RCSF. And a more uniform distribution interval of equivalent strain and thickness are got by FCSF. The minimum transitional length of formed part decreases with the increases of forming radius, and the minimum transitional length of RCSF is larger than that of FCSF. The experiment of spherical part shows that FCSF technology is excellent to form 3D parts with large transversal curvature and short transitional length, which proves that the FCSF technology is feasible and the simulated results are valid.

\section{Acknowledgement}

This project was sponsored by Shanghai Rising-Star Program (B type) (16QB1400800).

\section{References}

[1] Z.H. Zhou, Z.Y. Cai and M.Z. Li: Journal of Jilin University (Engineering Technology Edition) Vol. 35 (2005), pp. 287 (in Chinese)

[2] M.Z. Li, Y.H. Liu, S.Z. Su and G.Q. Li: Journal of Materials Processing Technology, Vol. 87 (1999), p. 227

[3] Z.Y. Cai, S.H. Wang and D.X. Xu, M.Z. Li: Journal of Materials Processing Technology, Vol. 209 (2009), p. 396-407

[4] S.H. Wang, Z.Y. Cai, and M.Z. Li: The International Journal of Advanced Manufacturing Technology, Vol. 49 (2010), p. 475

[5] Information on http://www.acb-ps.com/en/article.php3?id_article=1

[6] X. Chen, M.Z. Li, W.Z. Fu and P.X. Feng: Forging and stamping technology, Vol. 35 (2010), p. 32 (in Chinese) 